\title{
Retarded Onchocerca volvulus L1 to L3 larval development in the Simulium damnosum vector after anti-wolbachial treatment of the human host
}

Anna Albers ${ }^{1 \dagger}$, Mathias Eyong Esumm $2,3+$, Nicholas Tendongfor ${ }^{2,4}$, Peter Enyong ${ }^{2}$, Ute Klarmann ${ }^{1,5}$, Samuel Wanji ${ }^{2,4}$, Achim Hoerauf ${ }^{1}$ and Kenneth Pfarr ${ }^{1 *}$

\begin{abstract}
Background: The human parasite Onchocerca volvulus harbours Wolbachia endosymbionts essential for worm embryogenesis, larval development and adult survival. In this study, the development of Wolbachia-depleted microfilariae (first stage larvae) to infective third stage larvae (L3) in the insect vector Simulium damnosum was analysed.
\end{abstract}

Methods: Infected volunteers in Cameroon were randomly and blindly allocated into doxycycline $(200 \mathrm{mg} /$ day for 6 weeks) or placebo treatment groups. After treatment, blackflies were allowed to take a blood meal on the volunteers, captured and dissected for larval counting and DNA extraction for quantitative real-time PCR analysis.

Results: PCR results showed a clear reduction in Wolbachia DNA after doxycycline treatment in microfilariae from human skin biopsies with $>50 \%$ reduction at one month post-treatment, eventually reaching a reduction of $>$ $80 \%$. Larval stages recovered from the insect vector had similar levels of reduction of endosymbiotic bacteria. Larval recoveries were analysed longitudinally after treatment to follow the kinetics of larval development. Beginning at three months post-treatment, significantly fewer L3 were seen in the blackflies that had fed on doxycycline treated volunteers. Concomitant with this, the proportion of second stage larvae (L2) was significantly increased in this group.

Conclusions: Doxycycline treatment and the resulting decline of Wolbachia endobacteria from the microfilaria resulted in retarded development of larvae in the insect vector. Thus, anti-wolbachial treatment could have an additive effect for interrupting transmission by reducing the number of $\mathrm{L} 3$ that can be transmitted by blackflies.

Keywords: Onchocerca volvulus, Wolbachia, doxycycline, development, onchocerciasis

\section{Background}

Onchocerciasis, caused by Onchocerca volvulus, is endemic in many sub-Saharan countries with further foci in Latin America and Yemen [1,2]. The number of infections is estimated to be $\sim 37$ million $[3,4]$. The chronic nature and morbidity of onchocerciasis is associated with microfilariae (first stage larvae; Mf) that migrate

\footnotetext{
* Correspondence: pfarr@microbiology-bonn.de

† Contributed equally

'Institute for Medical Microbiology, Immunology and Parasitology, University Hospital Bonn, Sigmund-Freud-Str. 25, D-53105 Bonn, Germany

Full list of author information is available at the end of the article
}

through the skin and the eye. When the Mf die, the immune response to the dead larvae can result in dermatitis, skin atrophy and inflammation in the eyes. The latter can progress into reduced vision and blindness. Vector control and mass treatment with ivermectin, a strong microfilaricidal drug which can produce temporary sterility [5], have been successfully used to regionally reduce the burden of parasite infection. Due to the resumption of fertility after interruption of ivermectin treatment, the drug has to be administered for many years. Studies in Ghana have identified O. volvulus populations that are less responsive to ivermectin [6-10], 
therefore identification of new drug regimens is required before ivermectin resistance may develop and spread. Ideally a new drug would have macrofilaricidal and/or permanent sterilising activity.

In recent years, key drug trials have been performed with a new chemotherapeutical approach to anti-filarial therapy, the targeting of the essential Wolbachia endobacteria present in many filariae with the antibiotic doxycycline. This approach has resulted in long-term sterilisation of adult female worms in onchocerciasis [11-14]. More importantly, anti-wolbachial therapy also results in a macrofilaricidal effect in $O$. volvulus $[13,15,16]$.

Doxycycline affects several stages in the parasite life cycle. Embryonic stages from morulae to coiled Mf are the most sensitive to Wolbachia depletion $[13,15,16]$. The development from L3 (infective larval stage) into adult worms is also affected [17-20]. In the mammalian host, Mf are apparently unaffected by the decreased endobacterial load [12,17]. However, the effect of Wolbachia-depletion on $O$. volvulus larval development from Mf to L3 in the obligate arthropod vector remains unknown. Arumugam et al. showed that larvae of the rodent filaria Litomosoides sigmodontis were dependent upon the endosymbionts for development into infective L3 larvae in the mite vector [17]. Fewer female worms were able to develop from Wolbachia depleted Mf, because of their need of a higher threshold level of endobacteria to survive.

This study was designed to investigate whether Wolbachia endobacteria are essential for the transmission of onchocerciasis. To determine this, we analysed the role of Wolbachia in the development of O. volvulus Mf into L3 infective larvae in the Simulium vector by depleting the endobacteria from the Mf prior to their ingestion by blackflies during a blood meal.

\section{Methods}

\section{Ethical approval}

This study received ethical clearance from the Institutional Review Board of the Tropical Medicine Research Station, Kumba and was conducted in accordance with the Helsinki Declaration of 1975 as revised in 1983, 2000 and 2002.

\section{Selection of study patients and treatment}

In November and December 2006, participants for the study were recruited in four neighbouring villages in an onchocerciasis-endemic region of South West Cameroon (Figure 1). Patients for the study were selected from male volunteers, aged 21 to 50 years, after informed consent was signed. Exclusion criteria were abnormal hepatic (SGPT and SGOT) and renal (creatinine) functions, persons with chronic infections and under prolonged medication, alcohol abuse and intolerance to doxycycline. As there was mass treatment with ivermectin in the area in April 2006, all patients were asked whether they took their doses at this time or any time before, but all volunteers answered in the negative. Inclusion criteria were absence of other clinically manifested diseases as assessed by a medical doctor and $\geq 10$ Mf in skin biopsies. Two bloodless skin biopsies, one from each iliac crest of each participant, were aseptically obtained using a Holth corneoscleral punch. Each biopsy was immersed in 2 drops of $0.9 \% \mathrm{NaCl}$ solution in a separate well of a labelled 96-well round-bottom microtiter plate. The plates were transported to the laboratory and skin biopsies were incubated overnight at room temperature to allow the emergence of Mf into the saline solution. The Mf were counted using 10-fold magnification of a microscope and the number of $\mathrm{Mf}$ were expressed as Mf per skin biopsy.

Twelve volunteers were blindly allocated into two treatment groups. One group of 7 volunteers received doxycycline ( $200 \mathrm{mg} /$ day) for 6 weeks while the second group of 5 volunteers received matching placebo.

\section{Infection of wild Simulium flies with Onchocerca volvulus}

Before and after treatment, the volunteers were brought to a pre-selected $O$. volvulus-free capture point near a Simulium breeding site on the bank of the River Mungo to allow Simulium damnosum flies, the vector of O. volvulus, to take a blood meal. The site was chosen based on the results of dissection of wild Simulium flies to determine the natural parous, infection and infective rates, the latter two variables indicating that there was no O. volvulus endemic to the capture site (Table 1 ). These parameters were monitored throughout the study period. The fed flies were captured on the volunteers in small plastic containers. Containers for each volunteer were kept separately in plastic baskets. At least four hundred flies were caught from each patient in four days at each time point. Transport to the insectarium was carried out in cold boxes. The flies were then kept for 7 days at $25^{\circ} \mathrm{C}$ and $80 \%$ relative humidity to allow the Mf to develop into infective third stage larvae (L3).

Larvae were isolated from the flies by dissection using a dissecting microscope and their developmental stages were scored. The number of flies dissected at each time point varied due to different fly mortality rates. The isolated developmental stages of the larvae (L1, L2 and L3) were stored separately in $80 \%$ ethanol. At least two tubes each containing different numbers of L1, L2 and L3 isolated from flies fed on each volunteer at each time point were stored for later DNA extraction and quantification of Wolbachia. 


\section{\begin{tabular}{c|c|c}
$\begin{array}{c}\text { Patient } \\
\text { recruitment }\end{array}$ & $\begin{array}{c}\text { Pre- } \\
\text { treatment } \\
\mathbf{0 ~ m p t}\end{array}$ & $\begin{array}{l}6 \text { weeks trea } \\
\text { Doxycycline } \\
200 \mathrm{mg} / \text { day } \\
\text { Placebo }\end{array}$ \\
\hline Nov/Dec 2006 A) & A) + B) & Dec 2006 \\
\hline & $\begin{array}{ll}\text { B) Blood meal, } \\
\text { A) Skin biopsies }\end{array}$ \\
$\begin{array}{l}\text { Mf count } \\
\text { 7ays Insectarium, } \\
\text { dissection of flies, } \\
\text { larval count }\end{array}$
\end{tabular} \\ mpt (month(s) post treatment)}

Figure 1 Study timeline of recruitment, treatment and analysis. Patients were recruited in November/December 2006. After the informed consent was signed by each volunteer, skin biopsies were taken from which Mf were isolated and counted. Volunteers were allocated into two treatment groups. Before treatment with doxycycline or placebo (pre-treatment, month 0), volunteers were brought to the capture side to allow Simulium damnosum flies to take a blood meal. Flies were captured and raised in an insectarium for seven days. After dissecting the flies Onchocerca volvulus larvae were counted. This was repeated monthly for five months after doxycycline treatment was completed.

\section{Follow-up of volunteers and monitoring of Mf load after treatment}

During the following 5 months post-treatment, flies were captured on a monthly basis on the volunteers as described above (Figure 1). Skin biopsies were also obtained from the patients at each time point to assess their Mf load after the antibiotic treatment. After counting, the Mf were also stored in $80 \%$ ethanol for later quantitative PCR analysis to determine their Wolbachia content.

\section{Kinetics of larval development after anti-wolbachial therapy}

The total number of L1 (first larval stage), L2 (second larval stage) and L3 (third, infective larval stage) collected after dissection of the flies was calculated for doxycycline and placebo treated individuals. The proportion of each larval stage generated for that month in each group was calculated and plotted against the month of dissection to follow the kinetics of the development of larvae in both treatment groups. At pre-treatment and one month follow-up, the L1 and L2 larvae counts were combined.

\section{DNA extraction from larvae}

One tube each of the different stages of larvae (L1, L2 and L3) per time point preserved in ethanol was randomly selected for DNA extraction and quantification of Wolbachia. The larvae preserved in ethanol were first centrifuged at $1800 \mathrm{rpm}$ (Multifuge 4KR, LH400075006475 , Heraeus, Haunau, Germany) for five minutes. The ethanol was slowly removed with a pipette without disturbing the larvae, leaving $100 \mu \mathrm{l}$ of volume. These larvae were then suspended in the remaining ethanol and transferred to a new tube.

DNA was extracted using the QIAamp ${ }^{\circledR}$ DNA mini Kit (Qiagen, Hilden, Germany) following the tissue protocol of the kit with the following modifications to achieve the maximum amount of quality DNA. The incubation period with proteinase $\mathrm{K}$ (Qiagen) was extended from $10 \mathrm{~min}$ to overnight at $56^{\circ} \mathrm{C}$. Wash buffers 1 and 2 were increased to $700 \mu$ followed by elution with $2 \times 50 \mu \mathrm{l}$ of $\mathrm{AE}$ buffer. For each elution step, the columns were incubated with AE buffer for 5 minutes at room temperature prior to centrifugation.

\section{Quantitative real-time PCR}

To determine the amount of Wolbachia in the larvae isolated from the vector captured after having fed on doxycycline or placebo treated individuals, the purified DNA samples of randomly selected larvae for each volunteer and time point were analysed by quantitative real-time PCR. Primers and hybridisation probe were

Table 1 Endemicity of Onchocerca volvulus infection in Simulium damnosum flies, Mungo river Etam, Cameroon

\begin{tabular}{|c|c|c|c|c|c|c|}
\hline Date & Flies captured & Flies dissected & Parous (\%) & Nulliparous (\%) & Infected (\%) & Infective (\%) \\
\hline June 2006 & 702 & 702 & $\begin{array}{c}256 \\
(36.5)\end{array}$ & $\begin{array}{c}446 \\
(63.5)\end{array}$ & $\begin{array}{c}2 \\
(0.78)\end{array}$ & $\begin{array}{c}0 \\
(0.0)\end{array}$ \\
\hline July 2006 & 483 & 483 & $\begin{array}{c}46 \\
(9.5)\end{array}$ & $\begin{array}{c}437 \\
(90.5)\end{array}$ & $\begin{array}{c}0 \\
(0.0)\end{array}$ & $\begin{array}{c}0 \\
(0.0)\end{array}$ \\
\hline September 2006 & 537 & 537 & $\begin{array}{c}36 \\
(6.7)\end{array}$ & $\begin{array}{c}501 \\
(93.3)\end{array}$ & $\begin{array}{c}0 \\
(0.0)\end{array}$ & $\begin{array}{c}0 \\
(0.0)\end{array}$ \\
\hline Total & 1722 & 1722 & $\begin{array}{c}338 \\
(19.6)\end{array}$ & $\begin{array}{c}1384 \\
(80.4)\end{array}$ & $\begin{array}{c}2 \\
(0.59)\end{array}$ & $\begin{array}{c}0 \\
(0.0)\end{array}$ \\
\hline
\end{tabular}


designed with Primer3 software [21] for the O. volvulus Wolbachia ftsZ gene (GenBank accession No. AJ276501), which codes for a single-copy cell division protein. For all samples, the following master mix was used: $1 \times$ QuantiTect $^{\mathbb{B}}$ Virus NR Master Mix (Qiagen), $300 \mathrm{nM}$ each forward and reverse primers (Table 2), 50 $\mathrm{nM}$ TaqMan hybridisation probe with the fluorescent dye 6-FAM (6-carboxyfluorescein) and Tamra (Biomers, Ulm, Germany) and $10 \mu \mathrm{l}$ of sample DNA in a $20 \mu \mathrm{l}$ reaction. The PCR program utilised a two-step reaction of the following conditions in a Rotor Gene 6000 (Corbett Research, Sydney, Australia): $1 \times 5 \mathrm{~min}$ at $95^{\circ} \mathrm{C}, 45$ cycles of $94^{\circ} \mathrm{C}$ for $10 \mathrm{~s}$ and $58^{\circ} \mathrm{C}$ for $45 \mathrm{~s}$. Fluorescence was acquired on the FAM channel at $58^{\circ} \mathrm{C}$. A second PCR was performed to quantify $O$. volvulus $\beta$-actin (GenBank accession no. M84916) to normalise the fts $Z$ values [22]. The optimised PCR conditions were: $1 \times$ HotStar $^{\circledR}$ Taq Polymerase buffer (Qiagen), $4 \mathrm{mM}$ $\mathrm{MgCl}_{2}, 200 \mu \mathrm{M}$ dNTP, $300 \mathrm{nM}$ each forward and reverse primers (Table 2), $0.2 \mu \mathrm{l}$ of Sybr Green (1:1,000 diluted in DMSO, Roche, Mannheim, Germany), $2.5 \mathrm{U}$ HotStar $^{\circledR}$ Taq Polymerase and $2 \mu \mathrm{l}$ DNA in a $20 \mu \mathrm{l}$ reaction. The PCR profile used a 3-step program with an initial $95^{\circ} \mathrm{C}$ for $15 \mathrm{~min}$, followed by 35 cycles at $94^{\circ} \mathrm{C}$ for $10 \mathrm{~s}, 52^{\circ} \mathrm{C}$ for $15 \mathrm{~s}$ and finally $72^{\circ} \mathrm{C}$ for $15 \mathrm{~s}$. Fluorescence was acquired on the FAM channel at the end of the extension step.

In both PCR assays, each sample was analysed in triplicate. Every run contained a plasmid containing sequences specific for Wolbachia fts $Z$ or O. volvulus actin genes with a known number of copies for use as a standard. A no-template control of water instead of sample DNA was used as negative control. Copy numbers for each gene were calculated using a modification of the comparative quantification formula as described previously [23]. Using the Rotor Gene 6000 version 6.0 software the amplification (A) of each sample was calculated and the mean taken from replicate samples (sam). A plasmid containing either the fts $Z$ or $\beta$-actin sequence was quantified and copies/ $\mu$ l determined for use as a reference (ref) in each PCR run. The amplification factor of the sample compared to the specific reference was

Table 2 Primer and Probe sequences for quantification of the Wolbachia fts $Z$ and Onchocerca volvulus $\beta$-actin genes

\begin{tabular}{lll}
\hline Gene target & Name & Sequence $\mathbf{5}^{\prime} \mathbf{- 3}^{\prime}$ \\
\hline O. volvulus Wol ftsZ & Forward & aggaatgggtggtggtactg \\
O. volvulus Wol fts $Z$ & Reverse & ctttaaccgcagctcttgct \\
O. volvulus Wol ftsZ & Hybridization probe & ccttgccgctttcgcaatcac \\
O. volvulus $\beta$-actin & Forward & gtgctacgttgctttggact \\
O. volvulus $\beta$-actin & Reverse & gtaatcacttggccatcagg \\
Murine Interferon $\gamma$ & Forward & tcaagtggcatagatgtggaagaa \\
Murine Interferon $\gamma$ & Reverse & tggctctgcaggatttcatg \\
\hline
\end{tabular}

then calculated using the following formula: $A_{\text {ref }}{ }^{\wedge}$ take

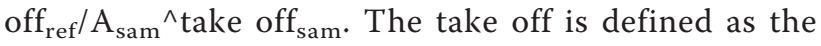
crossing point cycle where all measured samples are $20 \%$ above background. The amplification factor was then multiplied by the known concentration of the reference to give copies/ $\mu$ l. The fts $Z / \beta$-actin ratio was then calculated.

To exclude inhibition of the PCR reaction by inhibitors in the DNA a third PCR with a plasmid containing a fragment of the murine Interferon- $\gamma$ gene was performed in the presence of the extracted DNA. The samples were set up for real-time PCR with a master mix containing $1 \times$ HotStar $^{\circledR}$ Taq Polymerase buffer (Qiagen), $200 \mu \mathrm{m}$ dNTP, $400 \mathrm{nM}$ each of forward and reverse primer (Table 2), $0.2 \mu \mathrm{lSYBR}^{\circledR}$ Green (1:1000 diluted in DMSO, Roche, Mannheim, Germany), 2.5 units HotStar ${ }^{\circledR}$ Taq Polymerase, $2 \mu$ reference Plasmid DNA and $2 \mu \mathrm{l}$ sample DNA in a $20 \mu \mathrm{l}$ reaction. The PCR profile was: $1 \times 15 \mathrm{~min}$ at $95^{\circ} \mathrm{C}, 45$ cycles of $94^{\circ} \mathrm{C}$ for $15 \mathrm{~s}, 58^{\circ} \mathrm{C}$ for $20 \mathrm{~s}, 72^{\circ} \mathrm{C}$ for $20 \mathrm{~s}$. Fluorescence was acquired on the FAM channel. An increase in cycle number of $\geq 1$ cycle over the plasmid-only sample indicated the presence of PCR inhibitors in the DNA extracted from the larvae.

\section{Data analysis and statistics used}

To test the interaction of treatment and time, we calculated the difference between follow-up time-points and pre-treatment regarding the percentages of L3-larvae to account for the development between pre-treatment and after treatment in each patient. A repeated measures ANOVA was then performed using PASW 18 (IBM, Chicago, USA). The proportions of different larval stages were analysed by calculating the L3/total larvae and L1 + L2/total larvae ratios. Statistical significance between larvae from vectors fed on doxycycline or placebo treated individuals was determined with the Mann Whitney $\mathrm{U}$ test ( $\mathrm{P} \leq 0.05$ was considered significant) using PASW 18. Results were presented using the median. Larval recoveries were expressed as median with $10-90^{\text {th }}$ percentiles. Wolbachia quantities determined by PCR were expressed as the ratio of $f t s Z / \beta$-actin.

\section{Results}

\section{Selection of Onchocerca volvulus-free Simulium capture} site

Before bringing $O$. volvulus infected volunteers to the blackfly capture site, we determined the natural parous and infection rates by collecting and dissecting wild Simulium flies. A total of 1722 female flies were collected in June, July and September of 2006. The flies were dissected and $O$. volvulus infection status determined: $19.6 \%$ were parous (females are reproductively mature) of which $2(0.59 \%)$ were infected, but did not 
contain infective stage larvae (Table 1). Thus, the local blackfly population was sexually mature, seeking blood meals, and their river location was essentially free of endogenous $O$. volvulus infections.

\section{Kinetics of larval development}

To determine the skin microfilarial loads and recovery of O. volvulus larvae from flies that had fed on doxycycline or placebo treated individuals, skin biopsies and dissected flies were analysed for developing larvae. Mf were counted and expressed as Mf per skin biopsy. The median number of L1, L2, and L3 larvae collected after fly dissection was calculated per treatment group (Table 3 ). Because the number of flies that were dissected from each volunteer was different due to different numbers recovered at the biting site and different survival rates in the insectarium, the proportions of each larval stage that developed in each treatment group were plotted against the month of dissection (month post-treatment) to follow the kinetics of larval development (Figure 2). A repeated measures ANOVA determined that there was a significant difference in L3 recovery between the 5 measurement time-points $(\mathrm{P}<0.001$, Pillai-Spur) but no clear interaction between the measurement timepoints and the treatment $(\mathrm{P}=0.092$, Pillai-Spur $)$, although the doxycycline group was different $(\mathrm{P}=$ 0.005).

Since there was no clear interaction, pair-wise comparisons between the treatment groups at each timepoint were performed. Starting three months post-treatment, differences in the median recovery of L1+L2 and L3 from flies fed on the doxycycline treated volunteers were seen. The proportions of $\mathrm{L} 1+\mathrm{L} 2$ larvae recovered from flies that had fed on doxycycline treated individuals were higher at 3,4 and 5 months post- treatment (Figure 2). At three and five months post-treatment, the differences were significant compared to placebo $(\mathrm{P}<0.05$, Mann-Whitney $\mathrm{U}$ test). Correspondingly, beginning at three months post-treatment, a decrease in the proportion of L3 that developed in flies that had fed on doxycycline treated individuals as compared to placebo treated individuals was observed, with a significant difference seen for months 3 and 5 ( $\mathrm{P}<$ 0.05, Mann-Whitney U test; Figure 2).

\section{Wolbachia depletion after treatment with doxycycline}

To analyse the effect of treatment with antibiotic on the bacterial endosymbionts of $O$. volvulus $\mathrm{Mf}$ from the skin and larvae isolated from the vector, a quantitative realtime PCR assay was established for the O. volvulus Wolbachia fts $Z$ gene. The detection limit of the PCR was increased to $30 \mathrm{fts} Z$ copies ( $1 \mathrm{fts} Z=1$ Wolbachia) compared to our previous study [13]. For normalisation to worm material in the individual sample, a second PCR assay for $O$. volvulus $\beta$-actin was performed [22].

Compared to the placebo group, fewer samples were positive for $f t s Z$ above the PCR detection limit in the Mf from doxycycline treated individuals at 2, 3, 4 and 5 months post-treatment. Analysis of the Mf from skin biopsies showed a $>50 \%$ reduction in the number of Wolbachia one month post-treatment in the doxycycline treated group (Table 4). Wolbachia reduction further increased to $81 \%$ in the follow-up time points. At the two month follow-up only $2 / 6$ Mf samples (33\%) gave a positive $f t s Z$ signal in the PCR, and further decreased to only $1 / 7$ samples (14\%) being fts $Z$ positive at the 5 month follow-up. A similar pattern was seen in all larval stages collected from the vector. In contrast, in the

Table 3 Larval recoveries from skin snips and blood-fed black flies of doxycycline and placebo treated volunteers

\begin{tabular}{|c|c|c|c|c|c|c|}
\hline \multirow[b]{2}{*}{ Month $^{a}$} & \multicolumn{2}{|c|}{ Mf } & \multicolumn{2}{|c|}{ L1/L2 } & \multicolumn{2}{|c|}{ L3 } \\
\hline & $\begin{array}{l}\text { Doxy } \\
n=7\end{array}$ & $\begin{array}{c}\text { Placebo } \\
\mathrm{n}=5\end{array}$ & $\begin{array}{c}\text { Doxy } \\
\mathrm{n}=7^{\mathrm{c}}\end{array}$ & $\begin{array}{c}\text { Placebo } \\
\mathrm{n}=5\end{array}$ & $\begin{array}{l}\text { Doxy } \\
n=7\end{array}$ & $\begin{array}{c}\text { Placebo } \\
n=5\end{array}$ \\
\hline$\overline{0}$ & $\begin{array}{c}26^{\mathrm{d}} \\
(13-80)\end{array}$ & $\begin{array}{c}25 \\
(10-76)\end{array}$ & $\begin{array}{c}52 \\
(45-157)\end{array}$ & $\begin{array}{c}124 \\
(71-155)\end{array}$ & $\begin{array}{c}703 \\
(509-1214)\end{array}$ & $\begin{array}{c}789 \\
(396-941)\end{array}$ \\
\hline 1 & $\begin{array}{c}42 \\
(32-148) \\
\end{array}$ & $\begin{array}{c}83 \\
(31-221) \\
\end{array}$ & $\begin{array}{c}29 \\
(3-178) \\
\end{array}$ & $\begin{array}{c}33 \\
(7-69) \\
\end{array}$ & $\begin{array}{c}281 \\
(150-607) \\
\end{array}$ & $\begin{array}{c}313 \\
(226-516) \\
\end{array}$ \\
\hline 2 & $\begin{array}{c}40 \\
(8-92)\end{array}$ & $\begin{array}{c}114 \\
(15-192)\end{array}$ & $\begin{array}{c}133 \\
(28-524)\end{array}$ & $\begin{array}{c}112 \\
(42-294)\end{array}$ & $\begin{array}{c}797 \\
(211-1615)\end{array}$ & $\begin{array}{c}666 \\
(385-963)\end{array}$ \\
\hline 3 & $\begin{array}{c}13 \\
(7-40)\end{array}$ & $\begin{array}{c}27 \\
(10-113) \\
\end{array}$ & $\begin{array}{c}678 \\
(167-965)\end{array}$ & $\begin{array}{c}390 \\
(90-877)\end{array}$ & $\begin{array}{c}709 \\
(335-1070)\end{array}$ & $\begin{array}{c}983 \\
(487-1169\end{array}$ \\
\hline 4 & $\begin{array}{c}9 \\
(2-127) \\
\end{array}$ & $\begin{array}{c}63 \\
(9-92) \\
\end{array}$ & $\begin{array}{c}397 \\
(103-1218) \\
\end{array}$ & $\begin{array}{c}217 \\
(118-625) \\
\end{array}$ & $\begin{array}{c}318 \\
(71-593) \\
\end{array}$ & $\begin{array}{c}406 \\
(247-542) \\
\end{array}$ \\
\hline 5 & $\begin{array}{c}28 \\
(4-83)\end{array}$ & $\begin{array}{c}63 \\
(4-105)\end{array}$ & $\begin{array}{c}426 \\
(201-1476)\end{array}$ & $\begin{array}{c}575 \\
(388-1128)\end{array}$ & $\begin{array}{c}53 \\
(17-320)\end{array}$ & $\begin{array}{c}240 \\
(116-504)\end{array}$ \\
\hline
\end{tabular}

\footnotetext{
${ }^{a}$ Month after treatment (Group 0 is pre-treatment)

${ }^{\mathrm{b}}$ Treatment with Doxycycline (200 mg/day) for 6 weeks

c At 2 months post treatment only 6/7 doxycycline treated volunteers attended the follow-up meeting

${ }^{\mathrm{d}}$ Median (range)
} 


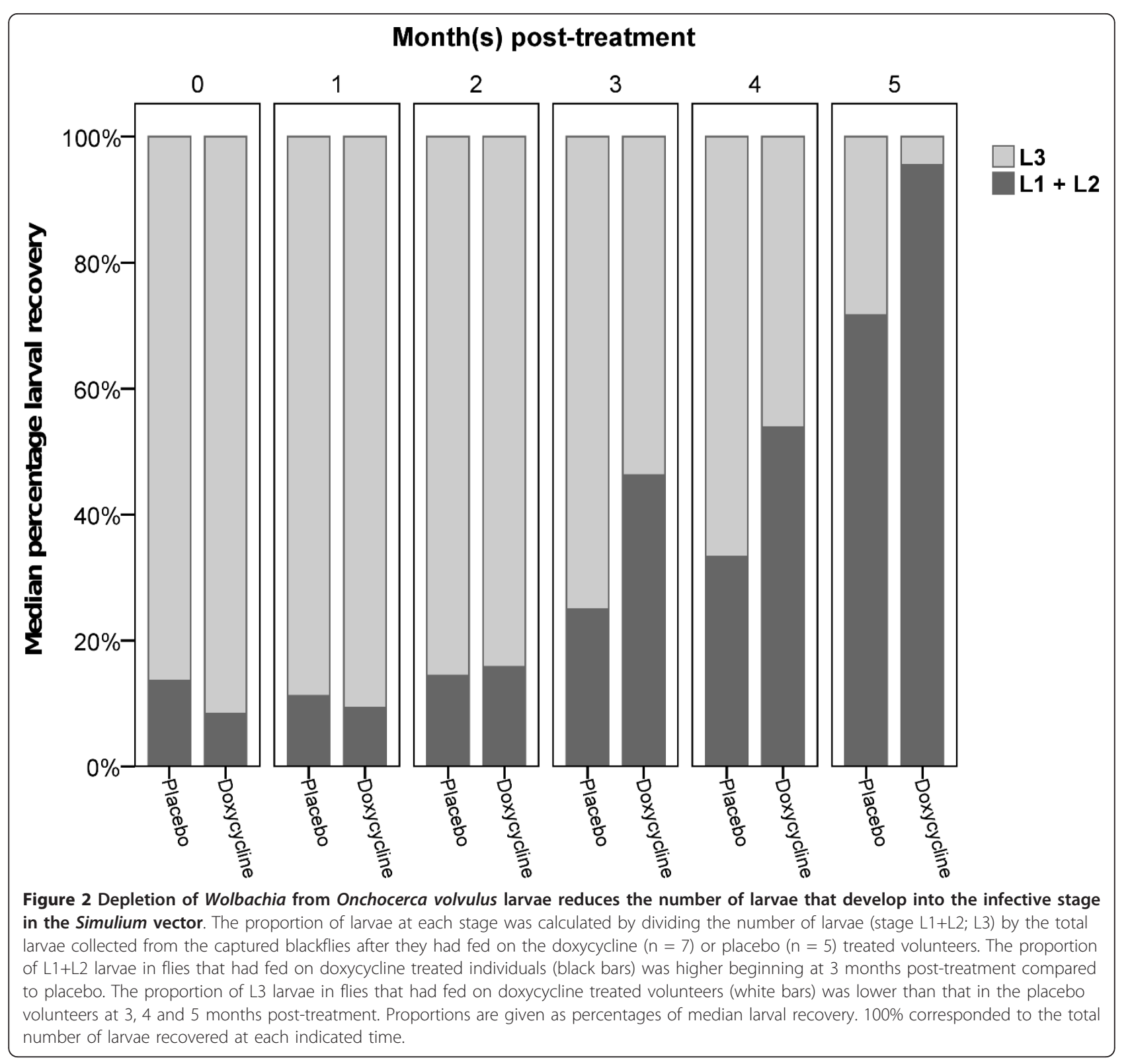

placebo group, almost every larval stage at each time point produced a clear signal above the detection limit for bacterial ftsZ. Only two placebo samples (L1 at pretreatment and L2 at month 2 post-treatment) did not have a signal above the fts $Z$ detection limit. These samples also gave a weak signal for actin (data not shown), indicating a very low DNA content. For all samples, a PCR test for inhibition did not show any inhibition by the sample. The negative $f t s Z$ samples therefore did not result from inhibitory factors in the DNA.

\section{Discussion}

In previous studies much work has been done showing the requirement of Wolbachia for oogenesis, embryogenesis and adult worm survival in infections with the filarial parasite $O$. volvulus $[11,12]$. Other studies have analysed the effects of tetracycline on larval development in the mammalian host. Tetracycline administered concomitantly with the start of infection with $L$. sigmodontis led to significant growth retardation in worms [24]. Oral treatment with tetracycline inhibited Brugia pahangi and Brugia malayi development from L3 to adult worms in Mongolian gerbils [18-20,25].

Different to animal models, little is known in human infection about the effects of antibiotic treatment of the mammalian host on the larval development in the insect vector. Therefore, the focus of this study was to analyse whether Mf from $O$. volvulus infected patients who had 
Table 4 Effect of doxycycline and placebo treatment on Wolbachia loads in larval worms: results quantitative PCR

\begin{tabular}{|c|c|c|c|c|c|c|c|c|}
\hline \multirow[b]{2}{*}{ Month $^{\mathrm{a}}$} & \multicolumn{2}{|c|}{ Mf (skin) } & \multicolumn{2}{|c|}{ L1 (vector) } & \multicolumn{2}{|c|}{ L2 (vector) } & \multicolumn{2}{|c|}{ L3 (vector) } \\
\hline & Doxy $^{b}$ & Placebo & Doxy & Placebo & Doxy & Placebo & Doxy & Placebo \\
\hline 0 & $\begin{array}{c}7 / 7^{c} \\
(0.06)^{d}\end{array}$ & $\begin{array}{c}5 / 5 \\
(0.02)\end{array}$ & $\begin{array}{c}7 / 7 \\
(0.058)\end{array}$ & $\begin{array}{c}4 / 5 \\
(0.03)\end{array}$ & $\bar{e}$ & e & $\begin{array}{c}6 / 6 \\
(0.026)\end{array}$ & $\begin{array}{c}5 / 5 \\
(0.05)\end{array}$ \\
\hline 1 & $\begin{array}{c}6 / 7 \\
(0.024)\end{array}$ & $\begin{array}{c}4 / 4 \\
(0.05)\end{array}$ & $\begin{array}{c}4 / 7 \\
(0.002)\end{array}$ & $\begin{array}{c}5 / 5 \\
(0.06)\end{array}$ & $\bar{e}$ & $\mathrm{e}$ & $\begin{array}{c}3 / 7 \\
(0.008)\end{array}$ & $\begin{array}{c}5 / 5 \\
(0.03)\end{array}$ \\
\hline 2 & $\begin{array}{c}2 / 6 \\
(0.068)\end{array}$ & $\begin{array}{c}5 / 5 \\
(0.22)\end{array}$ & $0 / 6$ & $\begin{array}{c}5 / 5 \\
(0.11)\end{array}$ & $\begin{array}{c}1 / 6 \\
(0.007)\end{array}$ & $\begin{array}{c}4 / 5 \\
(0.06)\end{array}$ & $\begin{array}{c}2 / 6 \\
(0.011)\end{array}$ & $\begin{array}{c}5 / 5 \\
(0.05)\end{array}$ \\
\hline 3 & $\begin{array}{c}2 / 7 \\
(0.085)\end{array}$ & $\begin{array}{c}4 / 4 \\
(0.70)\end{array}$ & $\begin{array}{c}2 / 7 \\
(0.06) \\
\end{array}$ & $\begin{array}{c}5 / 5 \\
(0.41) \\
\end{array}$ & $\begin{array}{c}4 / 7 \\
(0.029)\end{array}$ & $\begin{array}{c}5 / 5 \\
(0.16) \\
\end{array}$ & $\begin{array}{c}4 / 7 \\
(0.059)\end{array}$ & $\begin{array}{c}5 / 5 \\
(0.19) \\
\end{array}$ \\
\hline 4 & $\begin{array}{c}3 / 7 \\
(0.085)\end{array}$ & $\begin{array}{c}5 / 5 \\
(0.30)\end{array}$ & $0 / 7$ & $\begin{array}{c}4 / 4 \\
(0.32)\end{array}$ & $\begin{array}{c}3 / 7 \\
(0.002)\end{array}$ & $\begin{array}{c}4 / 4 \\
(0.16)\end{array}$ & $\begin{array}{c}2 / 7 \\
(0.036)\end{array}$ & $\begin{array}{c}5 / 5 \\
(0.43)\end{array}$ \\
\hline 5 & $\begin{array}{c}1 / 7 \\
(0.167)\end{array}$ & $\begin{array}{c}5 / 5 \\
(0.56)\end{array}$ & $\begin{array}{c}3 / 7 \\
(0.001)\end{array}$ & $\begin{array}{c}3 / 3 \\
(0.08)\end{array}$ & $\begin{array}{c}1 / 7 \\
(0.002)\end{array}$ & $\begin{array}{c}4 / 4 \\
(0.09)\end{array}$ & $\begin{array}{c}3 / 6 \\
(0.017)\end{array}$ & $\begin{array}{c}5 / 5 \\
(0.12)\end{array}$ \\
\hline
\end{tabular}

a Month after treatment

b Treatment with Doxycycline (200 mg/day) for 6 weeks

c Number of Wolbachia fts $Z$ positive volunteers

${ }^{\mathrm{d}}$ Median $\mathrm{fts} Z / \beta$-actin ratio

${ }^{\mathrm{e}} \mathrm{L} 1$ and L2 counts were combined at months 0 and 1 of the study

been treated with doxycycline, and thus had reduced or absent Wolbachia levels, could still develop into the infective third stage larvae (L3) in the Simulium vector.

Simulium flies were allowed to bite $O$. volvulus infected volunteers, then captured, raised in an insectarium and then dissected to count larvae that had developed. Prior to bringing the infected volunteers to the capture site, wild Simulium flies were captured and dissected to determine the natural parous, infection and infective rates. The very low infection $(0.59 \%)$ of the wild Simulium flies minimised the chance of an already infected fly feeding on the study volunteers (Table 1).

Our results show that Mf treated with doxycycline, and therefore depleted of their Wolbachia, developed into L3 at a considerably lower rate than Mf from placebo treated patients during the observation period. This was most apparent as a decrease of L3 with a corresponding increase of L1 and L2 seen in the doxycycline group at 3, 4 and 5 months post-treatment (Figure 2). Whether the few remaining L3 with low numbers of Wolbachia might be able to establish an infection in humans remains an open question that is technically and ethically impossible to answer for O. volvulus infections.

To support the requirement of Wolbachia during larval development, the depletion of the endobacteria was verified by a quantitative PCR assay for the Wolbachia $f t s Z$ gene. The PCR results showed a clear reduction of Wolbachia fts $Z$ in the Mf after one month of antibiotic treatment (52\% compared to placebo), with Mf from fewer than $50 \%$ of volunteer samples even having detectable $f t s Z$ at 2, 3, 4 and 5 months post-treatment (Table 4). In the few doxycycline treated larval samples that had an fts $Z$ signal, there was a clear reduction of the $f t s Z / \beta$-actin ratio. Because so many of the treated samples were negative for $f t s Z$, the sample size was too small for a statistical test.

In addition to the above described effect on larval development in the insect vector, depletion of the $\mathrm{Wol}$ bachia from $O$. volvulus Mf could have two other beneficial effects. One possible benefit is a reduced chance of Wolbachia-depleted larvae establishing an infection. This is supported by work with the L. sigmodontis murine model of filarial infections and results from the fact that Wolbachia increase the number and degranulation of mast cells at the site of infection, resulting in greater vascular permeability [26]. This effect is linked to the TLR-2 innate immune receptor, which recognizes and is activated by Wolbachia molecules [27-29]. The second possible benefit is the reduction in pathology in already infected individuals. Mf are the primary inducers of pathology due to their induction of a strong immune response when they die [30]. Work with animal models and natural animal Onchocerca infections have shown the importance of Wolbachia in the nematodes for attracting immune cells to the site of infection and more importantly, a reduction in the damage done to the eye when the endobacteria are depleted [30-33].

Changes in the number of L3 that developed from Wolbachia-depleted Mf did not appear until 3 months post treatment. We hypothesize that whatever products that the endobacteria provided to the nematodes for proper development are stable for two months and had already been produced and made available to the $\mathrm{Mf}$ prior to the depletion of the Wolbachia. When these Mf are taken up by the vector, they are then able to continue their development until the endobacterial substances are depleted. A better understanding of this 
phenomenon will be developed as the basis for the requirement of Wolbachia by filarial nematodes is elucidated.

Although not significant, within the placebo group the number of L3 larvae recovered from the Simulium decreased over time post-treatment. This could be due to the fall in temperatures (from $28^{\circ} \mathrm{C}$ to $24^{\circ} \mathrm{C}$ ) in the area at these time points reducing the capacity of the Simuliae to support the infective L3 [34,35]. However, this has to be confirmed in other experiments. The results of a repeated measures ANOVA allowed us to conclude that there was no interaction between the time of measurement and treatment. Nevertheless, there is a significant difference in the L3 reduction observed between the doxycycline and the placebo treated volunteers (Figure 2).

Inhibition of larval development after antibiotic treatment has been observed in several other studies. In a murine model with L. sigmodontis, significantly fewer L3 developed in the intermediate host if Mf were depleted of their Wolbachia endobacteria with tetracycline treatment [17]. Furthermore, infection of jirds with Wolbachiadepleted L3 resulted in the development of very few female worms, while male worm numbers were unchanged. The few female worms that were able to develop from Wolbachia-depleted Mf had endobacteria levels equivalent to control worms indicating that these worms developed from Mf with a Wolbachia threshold needed for successful development of the larvae. Thus, the O. volvulus L3 that had successfully developed at 4 and 5 months post treatment developed from Mf with the minimum of Wolbachia endosymbionts to develop into L3.

In our study the larvae were not exposed to doxycycline within the insect vector. The treatment occurred before the blackflies had fed on the infected volunteers. Because doxycycline rapidly blocks embryogenesis by Wolbachia depletion [12], the Mf taken up by the flies during the blood meal could only be those present at the time of doxycycline treatment. Therefore we concluded that Wolbachia depletion alone causes the impairment of larval development and is not a direct effect of the antibiotic on the larvae.

As noted, issues of small sample size arose during some of our analyses. Although a clear difference in the number of L3 that developed between the doxycycline and placebo groups could be seen 4 months post-treatment, the difference was not significant $(P=0.088)$. Because there was a significant difference seen for this parameter at 3 and 5 months, we are confident that with a larger cohort of volunteers the difference seen at 4 months post-treatment would reach significance. Such a larger study should also take into account the drop in L3 development from pre-treatment to five months post-treatment in the placebo group and be planned during a season or an area where the ambient temperature does not differ by $4^{\circ} \mathrm{C}$. A larger sample size would also allow us to perform statistics on the quantitative PCR results. We would like to note that the statistics would only strengthen what we have already seen, i.e. larvae which developed from Wolbachia-depleted Mf did not have any or had very low levels of Wolbachia as detected by quantitative real-time PCR.

\section{Conclusions}

To our knowledge, this is the first study analysing the effects of antibiotic treatment of $O$. volvulus infected humans on larval development in the insect vector. These findings have epidemiological implications. The results clearly show that depletion of Wolbachia not only affects the larval stages and adult worms in the mammalian host, it also has negative effects on larval development in blackflies. The decrease in L3 production, even though it is not $100 \%$, could reduce the transmission potential of blackflies following treatment of communities with doxycycline to control onchocerciasis. Thus anti-wolbachial therapy for filarial infections would have an additive effect of interrupting transmission by 1) blocking embryogenesis, 2) macrofilaricidal activity and 3) reduction of the number of L3 that can be transmitted by blackflies that have fed on infected persons before the Mf have been cleared from the skin.

A recent report on community-directed delivery of doxycycline for the treatment of onchocerciasis indicated that the delivery of doxycycline for six weeks is achievable. The therapeutic coverage and the compliance treatment rate achieved in this study coupled to the known efficiency of doxycycline demonstrate that mass administration may be used in selected problem areas such as in areas co-endemic for loiasis to control onchocerciasis [36].

\section{Acknowledgements}

We thank the study volunteers for their participation in the study. We are grateful for financial support from the Volkswagen Foundation (grant 1/81306) and the European Commission (grant INCO-CT-2006-032321).

\section{Author details}

${ }^{1}$ Institute for Medical Microbiology, Immunology and Parasitology, University Hospital Bonn, Sigmund-Freud-Str. 25, D-53105 Bonn, Germany. ${ }^{2}$ Research Foundation for Tropical Diseases and the Environment, P.O. Box 474, Buea, Cameroon. ${ }^{3}$ Department of Plant and Animal Sciences, Faculty of Science, University of Buea, P.O. Box 63, Buea, Cameroon. ${ }^{4}$ Department of Biochemistry and Microbiology, Faculty of Science, University of Buea, P.O. Box 63, Buea, Cameroon. ${ }^{5}$ Institute for Medical Biometry, Informatics and Epidemiology, University Hospital Bonn, Sigmund-Freud-Str. 25, D-53105 Bonn, Germany.

Authors' contributions

AA performed DNA extraction and PCR analysis, compiled the data, and drafted the manuscript.

$\mathrm{AH}$ developed and monitored the project, analysed data and corrected the manuscript. 
KP oversaw PCR assay development, statistical analysis and corrected the manuscript.

MEE participated in patient recruitment, administration of doxycycline and placebo, performed dissection of flies and DNA extraction.

NT participated in patient recruitment, administration of doxycycline and placebo, performed dissection of flies, and performed initial larval recovery statistics

PE participated in patient recruitment and doxycycline treatment and performed dissection of flies.

SW developed and monitored the project, analysed data and corrected the manuscript.

UK performed statistical analysis

All authors read and approved the final manuscript.

\section{Competing interests}

The authors declare that they have no competing interests.

Received: 19 August 2011 Accepted: 11 January 2012

Published: 11 January 2012

\section{References}

1. Boatin BA, Richards FO Jr: Control of onchocerciasis. Adv Parasitol 2006, 61:349-394.

2. WHO: Onchocerciasis (River Blindness). WHO Fact Sheet 2000, 95.

3. Basañez MG, Pion SD, Churcher TS, Breitling L, Little MP, Boussinesq M: River Blindness: A success story under threat? PLoS Med 2006, 3.

4. WHO: Meeting of the International Task Force for Disease Eradication-11 January 2007. Wkly Epidemiol Rec 2007, 82:197-202.

5. Awadzi K, Attah SK, Addy ET, Opoku NO, Quartey BT: The effects of highdose ivermectin regimens on Onchocerca volvulus in onchocerciasis patients. Trans R SocTrop Med Hyg 1999, 93:189-194.

6. Awadzi K, Attah SK, Addy ET, Opoku NO, Quartey BT, Lazdins-Helds JK, Ahmed K, Boatin BA, Boakye DA, Edwards G: Thirty-month follow-up of sub-optimal responders to multiple treatments with ivermectin, in two onchocerciasis-endemic foci in Ghana. Ann Trop Med Parasitol 2004, 98:359-370.

7. Awadzi K, Boakye DA, Edwards G, Opoku NO, Attah SK, OseiAtweneboana MY, Lazdins-Helds JK, Ardrey AE, Addy ET, Quartey BT, Ahmed K, Boatin BA, Soumbey-Alley EW: An investigation of persistent microfilaridermias despite multiple treatments with ivermectin, in two onchocerciasis-endemic foci in Ghana. Ann Trop Med Parasitol 2004, 98:231-249.

8. Osei-Atweneboana MY, Awadzi K, Attah SK, Boakye DA, Gyapong JO, Prichard RK: Phenotypic evidence of emerging ivermectin resistance in Onchocerca volvulus. PLoS Negl Trop Dis 2011, 5:e998.

9. Osei-Atweneboana MY, Eng JK, Boakye DA, Gyapong JO, Prichard RK: Prevalence and intensity of Onchocerca volvulus infection and efficacy of ivermectin in endemic communities in Ghana: a two-phase epidemiological study. Lancet 2007, 369:2021-2029.

10. Taylor MJ, Awadzi K, Basanez MG, Biritwum N, Boakye D, Boatin B, Bockarie M, Churcher TS, Debrah A, Edwards G, Hoerauf A, Mand S, Matthews G, Osei-Atweneboana M, Prichard RK, Wanji S, Adjei O: Onchocerciasis Control: Vision for the Future from a Ghanian perspective. Parasit Vectors 2009, 2:7.

11. Hoerauf A, Mand S, Adjei O, Fleischer B, Büttner D: Depletion of Wolbachia endobacteria in Onchocerca volvulus by doxycycline and microfilaridermia after ivermectin treatment. Lancet 2001, 357:1415-1416.

12. Hoerauf $A$, Mand S, Volkmann L, Büttner M, Marfo-Debrekyei $Y$, Taylor M, Adjei O, Büttner DW: Doxycycline in the treatment of human onchocerciasis: kinetics of Wolbachia endobacteria reduction and of inhibition of embryogenesis in female Onchocerca worms. Microbes Infect 2003, 5:261-273

13. Hoerauf A, Specht S, Büttner M, Pfarr K, Mand S, Fimmers R, MarfoDebrekyei Y, Konadu P, Debrah AY, Bandi C, Brattig N, Larbi J, Batsa L, Adjei O, Büttner DW: Wolbachia endobacteria depletion by doxycycline as antifilarial therapy has macrofilaricidal activity in onchocerciasis: a randomized placebo-controlled study. Med Microbiol Immunol 2008, 197:295-311

14. Turner JD, Mand S, Debrah AY, Muehlfeld J, Pfarr K, McGarry HF, Adjei O, Taylor MJ, Hoerauf A: A randomized, double-blind clinical trial of a 3week course of doxycycline plus albendazole and ivermectin for the treatment of Wuchereria bancrofti infection. Clin Infect Dis 2006, 42:1081-1089.

15. Hoerauf A, Specht S, Marfo-Debrekyei Y, Buttner M, Debrah AY, Mand S, Batsa L, Brattig N, Konadu P, Bandi C, Fimmers R, Adjei O, Büttner DW: Efficacy of 5-week doxycycline treatment on adult Onchocerca volvulus. Parasitol Res 2009, 104:437-447.

16. Turner JD, Tendongfor N, Esum M, Johnston KL, Langley RS, Ford L, Faragher B, Specht S, Mand S, Hoerauf A, Enyong P, Wanji S, Taylor MJ: Macrofilaricidal activity after doxycycline only treatment of Onchocerca volvulus in an area of Loa loa co-endemicity: a randomized controlled trial. PLoS Negl Trop Dis 2010, 4:e660.

17. Arumugam S, Pfarr KM, Hoerauf A: Infection of the intermediate mite host with Wolbachia-depleted Litomosoides sigmodontis microfilariae: Impaired L1 to L3 development and subsequent sex-ratio distortion in adult worms. Int J Parasitol 2008, 38:981-987.

18. Bosshardt SC, McCall JW, Coleman SU, Jones KL, Petit TA, Klei TR: Prophylactic activity of tetracycline against Brugia pahangi infection in jirds (Meriones unquiculatus). J Parasitol 1993, 79:775-777.

19. Casiraghi M, McCall JW, Simoncini L, Kramer LH, Sacchi L, Genchi C, Werren $\mathrm{JH}$, Bandi C: Tetracycline treatment and sex-ratio distortion: a role for Wolbachia in the moulting of filarial nematodes? Int J Parasitol 2002, 32:1457-1468.

20. Smith HL, Rajan TV: Tetracycline inhibits development of the infectivestage larvae of filarial nematodes in vitro. Exp Parasitol 2000, 95:265-270.

21. Rozen S, Skaletsky H: Primer3 on the WWW for general users and for biologist programmers. Meth Mol Biol 2000, 132:365-386.

22. Gilbert J, Nfon CK, Makepeace BL, Njongmeta LM, Hastings IM, Pfarr KM, Renz A, Tanya VN, Trees AJ: Antibiotic chemotherapy of onchocerciasis: in a bovine model, killing of adult parasites requires a sustained depletion of endosymbiotic bacteria (Wolbachia species). J Infect Dis 2005, 192:1483-1493.

23. Meijerink J, Mandigers C, van de Locht L, Tonnissen E, Goodsaid F, Raemaekers J: A novel method to compensate for different amplification efficiencies between patient DNA samples in quantitative real-time PCR. J Mol Diag 2001, 3:55-61.

24. Hoerauf A, Nissen-Pähle K, Schmetz C, Henkle-Dührsen K, Blaxter ML, Büttner DW, Gallin MY, Al-Qaoud KM, Lucius R, Fleischer B: Tetracycline therapy targets intracellular bacteria in the filarial nematode Litomosoides sigmodontis and results in filarial infertility. J Clin Invest 1999, 103:11-18.

25. Chirgwin SR, Nowling JM, Coleman SU, Klei TR: Brugia pahangi and Wolbachia: the kinetics of bacteria elimination, worm viability, and host responses following tetracycline teatment. Exp Parasitol 2003, 103:16-26.

26. Specht S, Frank JK, Alferink J, Dubben B, Layland LE, Denece G, Bain O, Forster I, Kirschning CJ, Martin C, Hoerauf A: CCL17 controls mast cells for the defense against filarial larval entry. J Immunol 2011, 186:4845-4852.

27. Brattig NW, Bazzocchi C, Kirschning CJ, Reiling N, Büttner DW, Ceciliani F, Geisinger F, Hochrein H, Ernst M, Wagner H, Bandi C, Hoerauf A: The major surface protein of Wolbachia endosymbionts in filarial nematodes elicits responses through TLR2 and TLR4. J Immunol 2004, 173:437-445.

28. Johnston KL, Wu B, Guimaraes A, Ford L, Slatko BE, Taylor MJ: Lipoprotein biosynthesis as a target for anti-Wolbachia treatment of filarial nematodes. Parasit Vectors 2010, 3:99.

29. Turner JD, Langley RS, Johnston KL, Gentil K, Ford L, Wu B, Graham M, Sharpley F, Slatko B, Pearlman E, Taylor MJ: Wolbachia lipoprotein stimulates innate and adaptive immunity through Toll-like receptors 2 and 6 to induce disease manifestations of filariasis. J Biol Chem 2009, 284:22364-22378.

30. Tamarozzi F, Halliday A, Gentil K, Hoerauf A, Pearlman E, Taylor MJ: Onchocerciasis: the role of Wolbachia bacterial endosymbionts in parasite biology, disease pathogenesis, and treatment. Clin Microbiol Rev 2011, 24:459-468.

31. Brattig NW, Büttner DW, Hoerauf A: Neutrophil accumulation around Onchocerca worms and chemotaxis of neutrophils are dependent on Wolbachia endobacteria. Microbes Infect 2001, 3:439-446.

32. Pearlman E, Garhart CA, Grand DJ, Diaconu E, Strine ER, Hall LR: Temporal recruitment of neutrophils and eosinophils to the skin in a murine model for onchocercal dermatitis. Am J Trop Med Hyg 1999, 61:14-18.

33. Saint André A, Blackwell NM, Hall LR, Hoerauf A, Brattig NW, Volkmann L, Taylor MJ, Ford L, Hise AG, Lass JH, Diaconu E, Pearlman E: The role of endosymbiotic Wolbachia bacteria in the pathogenesis of river blindness. Science 2002, 295:1892-1895. 
34. Omar MS, Denke AM, Raybould JN: The development of Onchocerca ochengi (nematoda: filariodea) to the infective stage in Simulium damnosum s.l. with a note on the histochemical staining of the parasite. Tropenmed Parasitol 1979, 30:157-162.

35. Takaoka H, Ochoa JO, Juarez EL, Hansen KM: Effects of temperature on development of Onchocerca volvulus in Simulium ochraceum, and longevity of the simuliid vector. J Parasitol 1982, 68:478-483.

36. Wanji S, Tendongfor N, Nji T, Esum M, Che JN, Nkwescheu A, Alassa F, Kamnang G, Enyong PA, Taylor MJ, Hoerauf A, Taylor DW: Communitydirected delivery of doxycycline for the treatment of onchocerciasis in areas of co-endemicity with loiasis in Cameroon. Parasit Vectors 2009, 2:39.

doi:10.1186/1756-3305-5-12

Cite this article as: Albers et al: Retarded Onchocerca volvulus L1 to L3 larval development in the Simulium damnosum vector after antiwolbachial treatment of the human host. Parasites \& Vectors 2012 5:12.

\section{Submit your next manuscript to BioMed Central} and take full advantage of:

- Convenient online submission

- Thorough peer review

- No space constraints or color figure charges

- Immediate publication on acceptance

- Inclusion in PubMed, CAS, Scopus and Google Scholar

- Research which is freely available for redistribution

Submit your manuscript at www.biomedcentral.com/submit 